\title{
SIC RESONANT DEVICES FOR HIGH Q AND HIGH TEMPERATURE APPLICATIONS
}

\author{
$\underline{\text { S. Roy }}{ }^{*+}$, A.K. McIlwain ${ }^{+}$, R.G. DeAnna ${ }^{*}$, A.J. Fleischman", R.K. Burla", C.A. Zorman", and M. Mehregany ${ }^{*}$ \\ "Department of Electrical Engineering and Computer Science \\ ${ }^{+}$Department of Materials Science and Engineering \\ Case Western Reserve University, Cleveland, Ohio 44106
}

\author{
${ }^{\dagger}$ Department of Biomedical Engineering \\ The Cleveland Clinic Foundation \\ Cleveland, Ohio 44195
}

\author{
${ }^{+}$U.S. Army Research Laboratory \\ NASA Glenn Research Center \\ Cleveland, Ohio 44135
}

\begin{abstract}
Polycrystalline cubic silicon carbide (poly $\mathrm{SiC}$ ) lateral resonant devices have been fabricated by surface micromachining, packaged using ccramic-based matcrials and nickel wircbonding proccdures, and successfully operated over $<10^{-5}-760$ Torr and $22-950^{\circ} \mathrm{C}$ pressure and temperature ranges, respectively. Device $Q$ 's of $>100,000$ at $<10^{-5}$ Torr and resonant frequency drifts of $<18 \mathrm{ppm} / \mathrm{hr}$ under continuous operation have been determined using an electron microscope-based setup. Finite element analysis revealed that changes in resonant frequency with increasing temperature depend on the interplay between the decrease in Young's modulus of poly $\mathrm{SiC}$ and induced stresses in the suspension beams of the lateral resonant device, which occur due to mismatch in thermal expansion coefficients of the polySiC film and the underlying substrate.
\end{abstract}

\section{INTRODUCTION}

Micromachined polysilicon resonators are emerging as potential on-chip replacements for discrete oscillators and filters in high performance communication transceivers [1]. The integrated microelectromechanical polysilicon devices exhibit frequency selectivity characteristics that are superior to integrated $R C$ active filtering techniques based upon traditional electron devices. Micromachined resonator $Q$ 's of $>80,000$ under vacuum conditions and resonant frequency coefficients of $<10 \mathrm{ppm} /{ }^{\circ} \mathrm{C}$ have been reported [2]. In addition to high $Q$ transceiver components, the utility of polysilicon resonators has also been demonstrated in a number of other applications including mechanical properties testing, pressure sensing, and inertial navigation systems [3-5]. However, the electrical and mechanical properties of polysilicon begin to rapidly degrade at elevated temperatures $\left(>350^{\circ} \mathrm{C}\right)$, making it increasingly unsuitable for high temperature applications [6-8]. In contrast, $\mathrm{SiC}$ is well known for its mechanical characteristics, chemical inertness, high thermal conductivity, and electrical stability at temperatures well above $600^{\circ} \mathrm{C}[8,9]$. Although the material properties and microfabrication compatibility of $\mathrm{SiC}$ make it an attractive structural material for fabrication of high $Q$ and/or high temperature microelectromechanical devices, the development of $\mathrm{SiC}$ as a structural material has been limited by a combination of fabrication, packaging, and testing challenges.

This paper presents development of cubic polycrystalline $\mathrm{SiC}$ (poly $\mathrm{SiC}$ ) lateral resonant devices (subsequently called resonators) that are fabricated, packaged, and successfully operated over a wide range of pressures and temperatures. First, the fabrication of polySiC resonators by a surface micromachining process using $\mathrm{SiO}_{2}$, polysilicon, and nickel $(\mathrm{Ni})$ as the isolation, sacrificial, and contact metallization layers, respectively, is presented. Details of the resonator packaging scheme using ceramic-based materials and $\mathrm{Ni}$ wirebonding procedures are also outlined. Next, both optical and electron microscope-based experimental setups and protocols to investigate changes in resonator $Q$ with pressure and resonant frequency with temperature are described. Finally, resonator testing results are presented and the behavior of resonant frequency with temperature is examined using finite element analysis.

\section{FABRICATION}

The starting substrate for poly $\mathrm{SiC}$ film growth is prepared by depositing a $3.5 \mu \mathrm{m}$-thick polysilicon film by LPCVD on a $1.5 \mu \mathrm{m}$ thick $\mathrm{SiO}_{2}$ layer grown thermally on $100-\mathrm{mm}$ diameter, (100) $\mathrm{Si}$ wafers. A polySiC film with a nominal thickness of $2 \mu \mathrm{m}$ is grown at $1280^{\circ} \mathrm{C}$ in a cold-wall, rf-induction-heated, vertical APCVD reactor [10]. The polySiC film is then mechanically polished using a SiC slurry to reduce the surface roughness $(\mathrm{Ra})$ from $\sim 400 \AA$ on the as-grown film to $<40 \AA$. Figure 1 outlines the fabrication of

(a)

(b)

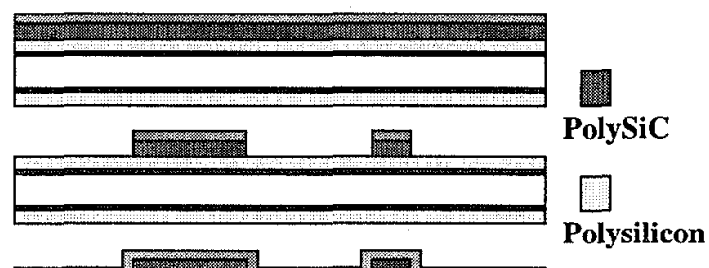

(c)

(d)

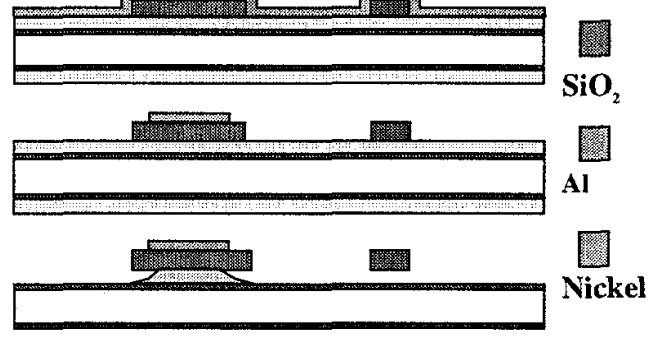

(e)

Figure 1. Schematic description of the polySiC resonator fabrication process showing cross-sections after: (a) Al deposition by sputtering; (b) definition of resonator pattern by plasma etching; (c) deposition of Ni by sputtering; (d) definition of $\mathrm{Ni}$ contact regions by photolithography and wet etching; and (e) release of poly $\mathrm{SiC}$ resonators in $\mathrm{KOH}$. 


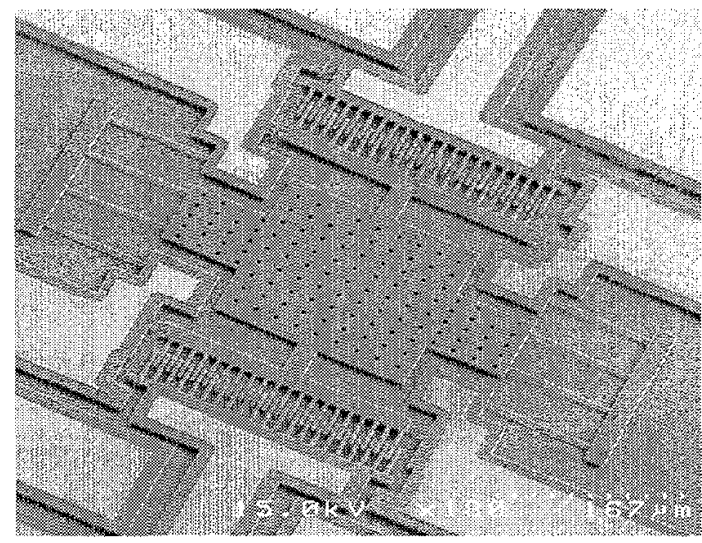

Figure 2. SEM micrograph of a released polySiC lateral resonant device. The suspension beam length and width are nominally $100 \mu \mathrm{m}$ and $2.5 \mu \mathrm{m}$, respectively. Exposed polySiC shows up as dark gray, while the Ni metallization appears light gray.

polySiC resonators by surface micromachining. A $5000 \AA$-thick aluminum (Al) film is deposited on the poly $\mathrm{SiC}$ film by sputtering and subsequently patterned using photolithography and $\mathrm{Al}$ etchant to delineate the resonator geometry. Next, the resonator pattern is defined in the polySiC by dry etching in a $\mathrm{CHF}_{3} / \mathrm{O}_{2} / \mathrm{He}$ plasma with $\mathrm{Al}$ acting as the etch mask [10]. Afterwards, the Al mask is stripped and a $7500 \AA$-thick $\mathrm{Ni}$ film is sputter deposited, patterned by photolithography, and wet etched to define nickel contacts to the polySiC. Finally, the resonator is released by a timed etch of the sacrificial polysilicon in $40 \mathrm{wt} \% \mathrm{KOH}$ at $40^{\circ} \mathrm{C}$ and dried using a supercritical $\mathrm{CO}_{2}$ drying process. Figure 2 presents a SEM micrograph of a released polySiC resonator.

The released polySiC resonator chip is packaged onto a ceramic plate with patterned gold pads and steel posts as shown in Fig. 3. The chip is attached to the ceramic plate using commercially available zirconia-based cement (AREMCO UltraTemp 516), which is thermally conductive, stable to $1760^{\circ} \mathrm{C}$, and resistant to chemical attack. The gold pads on the ceramic plate enable electrical connection from the resonator chip to external circuitry through the stainless steel screws, nuts, and washers. Electrical connections from the Ni contact pads on the resonator chip to the gold pads on the ceramic plate are realized by $25 \mu \mathrm{m}$ diameter $\mathrm{Ni}$ wires. Attachment of $\mathrm{Ni}$ wires to the pads is achieved by a thermosonic wirebonding process optimized for maximum pull strength [11].

\section{EXPERIMENTAL SETUPS}

The packaged resonators are tested under different conditions of pressure and temperature. Figure 4 presents the experimental setup used to test devices at atmospheric pressure (760 Torr). The resonator package is placed on a heater capable of attaining temperatures as high as $1000^{\circ} \mathrm{C}$. The heater is mounted on a thermally-insulating ceramic tile inside an aluminum chamber with openings for argon, electrical connections, and optical access. Probe tips are used to electrostatically actuate the resonator, while the microscope is used to monitor device motion. Argon is introduced at $\sim 2$ psi into the chamber during testing to minimize thermal oxidation effects on the probe tips and heater.

Figure 5 presents the experimental setup used to test devices under vacuum conditions. The resonator package is placed on a hot

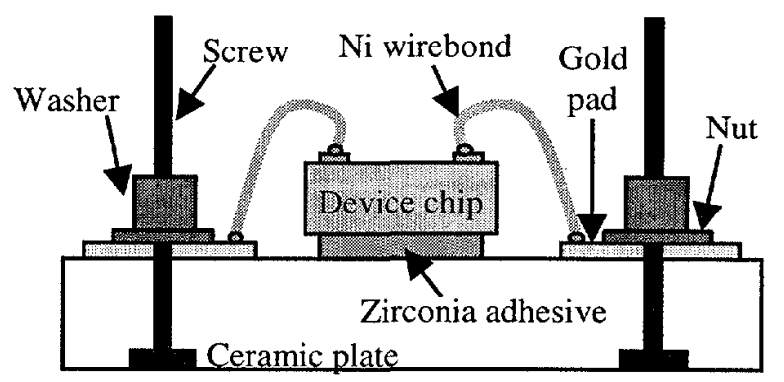

Figure 3. Cross-sectional schematic view of the polySiC resonator package. External electrical connections to the resonator chip are enabled through the stainless steel screws, washers, hex nuts, gold pads, and nickel wirebonds.

stage mounted inside an environmental SEM (ESEM) and connected to external circuitry via electrical feedthroughs. The resonator motion is observed using an attached monitor. In addition to room-temperature imaging capabilities of a standard SEM under high vacuum $\left(<10^{-5}\right.$ Torr $)$ conditions, the ESEM can also perform

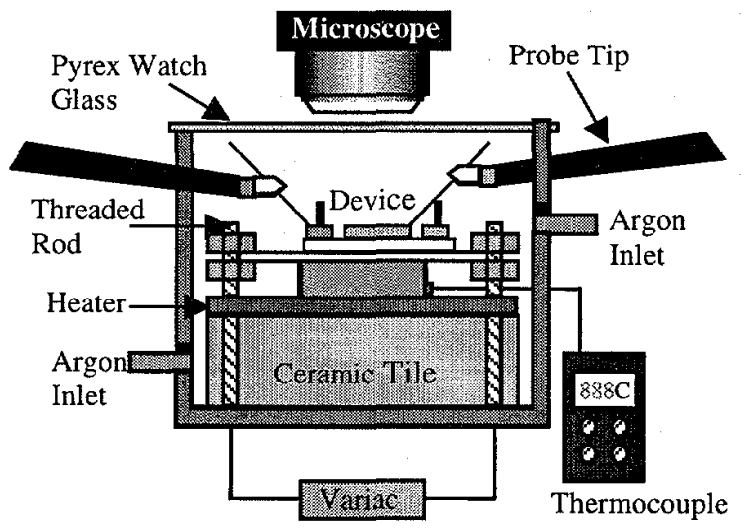

Figure 4. Test setup for atmospheric pressure (760 Torr) experiments. The optical microscope is used to observe resonator motion. Measurement uncertainty in resonant frequency is $\pm 50 \mathrm{~Hz}$.

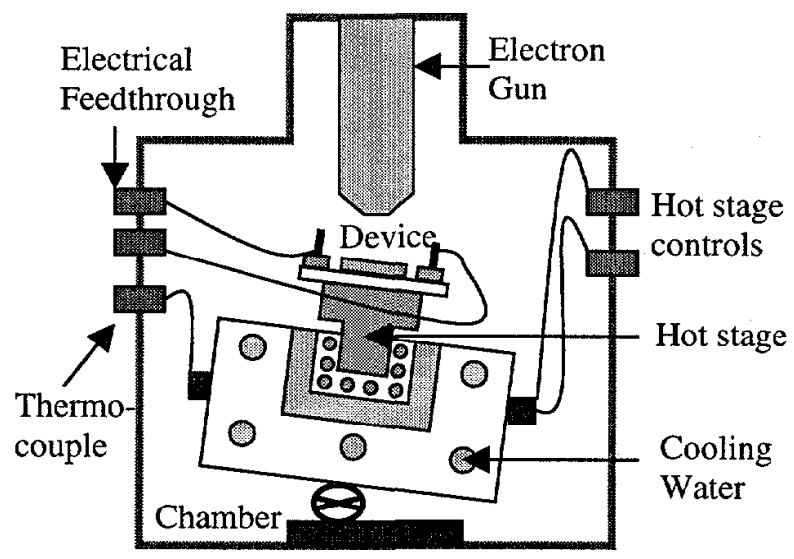

Figure 5. Schematic description of the environmental SEM setup used for experiments under vacuum conditions. Resonator motion is observed on an attached monitor. Measurement uncertainty in resonant frequency is $\pm 0.01 \mathrm{~Hz}$. 
imaging under low vacuum (0.1-20 Torr) and/or high temperature $\left(1000^{\circ} \mathrm{C}\right)$ conditions.

Experiments are performed to determine the resonant frequency and $Q$ of the resonator under different conditions of pressure and temperature. Resonant frequency is determined visually by adjusting the frequency of the excitation voltage to the resonator until maximum resonator amplitude is observed. Resonator $Q$ is determined from knowledge of the resonant frequency and $3 \mathrm{~dB}$ frequencies, which are defined as those frequencies at which resonator amplitude is $-70 \%$ of the maximum [12].

\section{RESULTS}

Table I presents a summary of resonator $Q^{\prime} s$ of three polySiC resonators measured at room temperature $\left(22^{\circ} \mathrm{C}\right)$ under three different pressure regimes. The low-pressure tests are conducted inside the ESEM, while the atmospheric pressure tests are performed using the optical microscope setup. The nominal resonator frequencies are determined under high vacuum conditions. The resonator $Q$ 's vary with pressure, with maxima and minima exhibited under high vacuum and atmospheric conditions, respectively. In general, resonator $Q$ 's are below 150 for all devices at 760 Torr, between 2500 and 4000 at 0.1-0.2 Torr, and above 50000 at $<10^{-5}$ Torr. This increase in resonator $Q$ with decreasing pressure is attributed to damping effects: at lower pressures, the damping is minimized and $Q$ is increased. The effect of damping on resonators is dominant for pressures down to $\sim 10^{-3}$ Torr, and at extremely low pressures (high vacuum conditions), the $Q$ is limited by the internal friction of polySiC [7, 13]. A 800 million cycle, $16 \mathrm{hr}$ aging test performed at $22^{\circ} \mathrm{C}$ on a $\sim 14 \mathrm{kHz}$ resonator reveals that the resonant frequency drift is approximately $17.5 \mathrm{ppm} / \mathrm{hr}$.

Figure 6 presents a graph showing the variation of resonant frequency with temperature for a polySiC resonator actuated at $150 \mathrm{Vpp}$ under atmospheric conditions. The corresponding resonant frequency drops from $30400 \mathrm{~Hz}$ at $22^{\circ} \mathrm{C}$ to $30000 \mathrm{~Hz}$ at $410^{\circ} \mathrm{C}$. The resonator does not operate above $500^{\circ} \mathrm{C}$ due to breakdown of the electrically isolating $\mathrm{SiO}_{2}$ layer. Figure 7 presents a graph showing the variation of resonant frequency with temperature for a comparable polySiC resonator under low vacuum (0.1-0.2 Torr) conditions. The device is actuated at $3.5 \mathrm{Vpp}$ and opcrates over a $22-950^{\circ} \mathrm{C}$ temperature range. The resonant frequency of the vacuum-tested device drops steadily from $28930 \mathrm{~Hz}$ at $22^{\circ} \mathrm{C}$ to $28402 \mathrm{~Hz}$ at $700^{\circ} \mathrm{C}$, followed by an increase to $28544 \mathrm{~Hz}$ at $900^{\circ} \mathrm{C}$, and then a slight decrease to 28500 at $950^{\circ} \mathrm{C}$.

Finite element analysis is performed to investigate changes in resonant frequency with increasing temperature. A preliminary finite element model is analyzed using ANSYS software to examine interactions between the polySiC resonator and silicon substrate [14]. The bottom of the silicon substrate is fixed in the direction normal to the surface and allowed free thermal expansion

Table I. Resonator $Q$ determined at different pressure regimes.

\begin{tabular}{|c|c|c|c|c|}
\hline $\begin{array}{c}\text { Device } \\
\#\end{array}$ & $\begin{array}{c}\mathbf{f}_{\mathrm{r}} \\
(\mathbf{H z})\end{array}$ & $\begin{array}{c}Q_{1} \\
( \pm 5 \%) \\
\end{array}$ & $\begin{array}{c}Q_{2} \\
( \pm 10 \%) \\
\end{array}$ & $\begin{array}{c}Q_{3} \\
( \pm 15 \%) \\
\end{array}$ \\
\hline 1 & 10060 & 25 & 2875 & 62888 \\
\hline 2 & 11360 & 34 & 3474 & 107926 \\
\hline 3 & 28920 & 148 & 3616 & 57828 \\
\hline
\end{tabular}

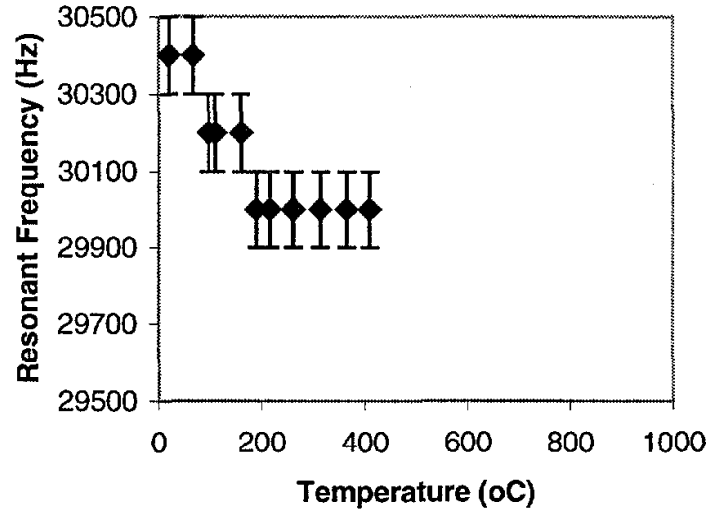

Figure 6. Variation of resonant frequency with temperature for a poly $\mathrm{SiC}$ resonator operated at atmospheric pressure at $150 \mathrm{Vpp}$ actuation. Device does not operate above $500^{\circ} \mathrm{C}$ due to breakdown of the insulating $\mathrm{SiO}_{2}$ layer.

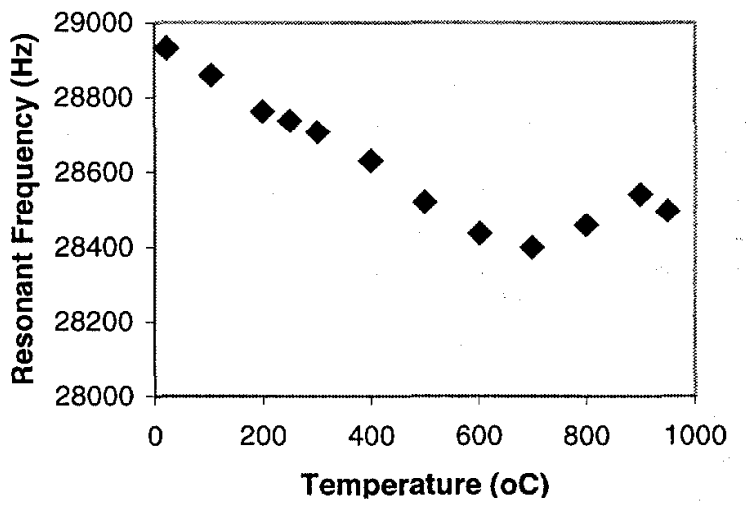

Figure 7. Variation of resonant frequency with temperature for a poly SiC resonator (comparable to the one in Fig. 6) under vacuum conditions (0.1-0.2 Torr) at 3.5Vpp actuation.

in directions parallel to the surface. Figure 8 presents a graph showing the variation of thermal expansion coefficients with temperature for cubic $\mathrm{SiC}$ (assumed equivalent to polySiC) and silicon, while Table II lists the other material properties used in the finite element analysis [14-16].

Figures 9 and 10 present graphs of normalized resonant frequency versus temperature based on the results of the finite element analysis and the experimental data shown in Fig. 7, respectively. In both cases, there is an initial steady decrease in resonant frequency, followed by a slight increase, and another slight decrease. The differences between the finite element results and expcrimental data may duc to variations between the actual material property parameters and those used in the model as well as the influence of intrinsic stresses in the various material layers.

Examination of the material properties used in the finite element model provides qualitative insight into the resonant frequency versus temperature behavior for the devices. The thermal expansion coefficient of polySiC is lower than that of silicon from $22^{\circ} \mathrm{C}$ to $-200^{\circ} \mathrm{C}$, while at higher temperatures, the thermal expansion coefficient of polySiC is greater than that of silicon. Consequently, at temperatures below $200^{\circ} \mathrm{C}$, the silicon substrate expands faster than the polySiC layer, which induces a resultant compressive thermal stress in the suspension beams of the 


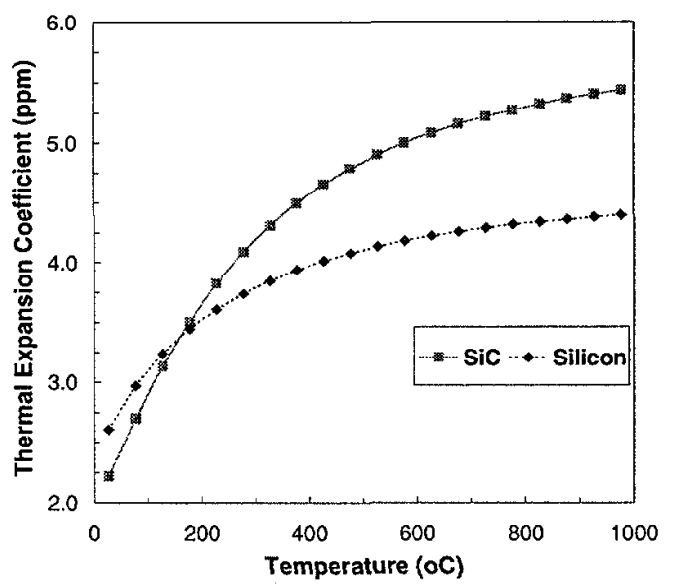

Figure 8. Variation of thermal expansion coefficient of SiC and silicon as a function of temperature [14-16].

Table II. Materials properties used in finite element analysis [14].

\begin{tabular}{|l|c|c|c|}
\hline \multicolumn{1}{|c|}{ Material } & $\begin{array}{c}\rho \\
\left(\mathbf{k g} / \mathbf{m}^{\mathbf{3}}\right)\end{array}$ & $\begin{array}{c}\mathbf{E} \\
(\mathbf{G P a})\end{array}$ & $\begin{array}{c}\alpha_{\mathbf{E}} \\
\left(\mathbf{p p m}^{\circ} \mathbf{C}\right)\end{array}$ \\
\hline \hline SiC & 3230 & 400 & 46 \\
\hline Silicon & 2320 & 160 & 80 \\
\hline
\end{tabular}

$\rho$ : density; E: Young's modulus; and $\alpha_{k}$ : temperature coefficient of Young's modulus.

resonator. The net effect of the induced compressive stress and decrease in Young's modulus of polySiC leads to a decrease in the resonant frequency. As temperatures increase above $200^{\circ} \mathrm{C}$, the polySiC film begins to expand faster than the silicon substrate, which induces a resultant tensile stress in the resonator suspension beams. The lowering effect on the resonant frequency due to the decrease in Young's modulus is counteracted by the induced tensile stress, which tends to increase resonant frequency. The net effect of increasing tensile stress and decreasing Young's modulus with increasing temperature leads to a resonant frequency minimum, and then, an increase. However, as the temperature increases even further, the effect of the decrease in Young's modulus dominates leading to the eventual decrease in resonant frequency.

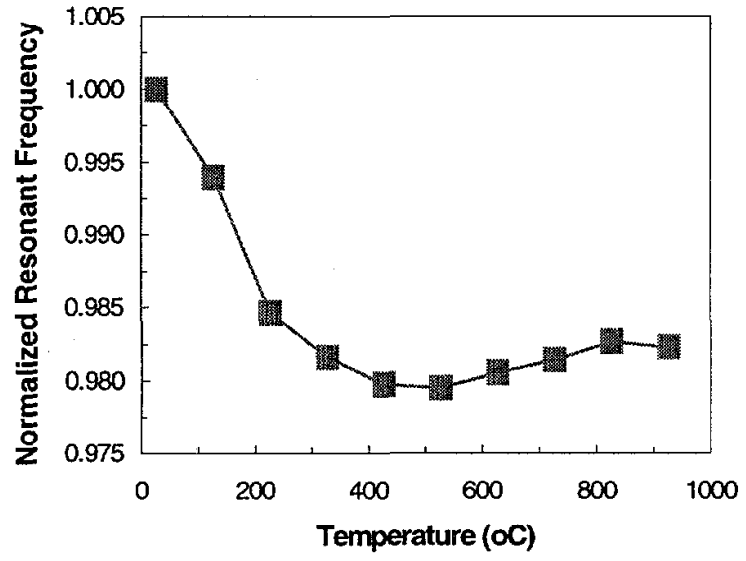

Figure 9. Predicted resonant frequency as a function of temperature obtained using finite element analysis.

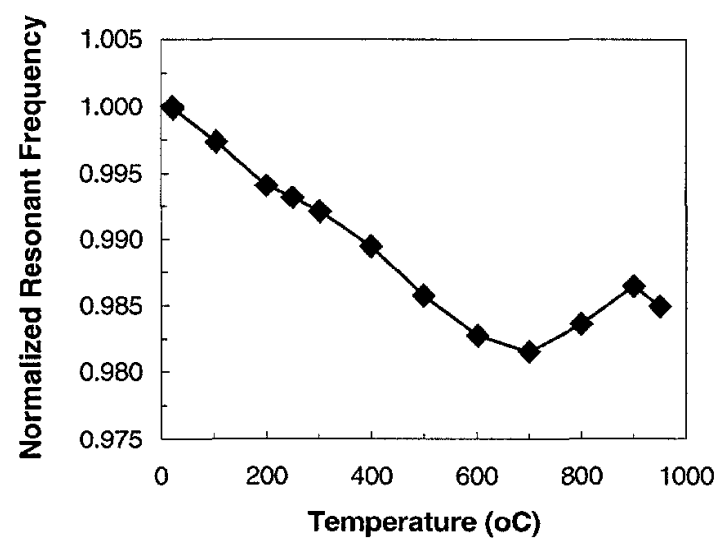

Figure 10. Normalized experimental data of Fig. 7.

\section{CONCLUSIONS}

PolySiC resonators have been fabricated by surface micromachining and successfully packaged for operation in vacuum and high temperature environments. Resonator Q's above 100,000 under vacuum conditions have been observed. Changes in resonant frequency with increasing temperature are attributed to a decrease in Young's modulus as well as thermal expansion mismatch with the underlying substrate.

\section{REFERENCES}

[1] C. T.-C. Nguyen, Proc. 1997 IEEE Intl. Symp.Circuits \& Syst., Hong Kong, (1997) pp. 2825-2828.

[2] C. T.-C. Nguyen and R. T. Howe, Tech. Dig., 1993 IEEE IEDM, Washington, D.C., (1993) pp. 199-202.

[3] H. Kahn, S. Stemmer, K. Nandakumar, A. H. Heuer, R. L. Mullen, R. Ballarini, and M. A. Huff, Proc. 1996 IEEE MEMS Wkshp., San Diego, CA, (1996) pp. 343-348.

[4] C. J. Welham, J. Greenwood, and M. M. Bertioli, Proc. 1998 Eurosens. XII, (1998) pp. 298-304.

[5] K. Funk, H. Emmerich, A. Schilp, M. Offenberg, R. Neul, and F. Laermer, Proc. 1999 IEEE MEMS Conf., Orlando, FL, (1999), pp. 57-60.

[6] G. Pearson, W. R. Jr., and W. Feldman, Act. Metall., v5, p. 181, 1957.

[7] M. Biebl, G. Brandl, and R. T. Howe, Proc. Intl. Conf. Solid-State Sens. \& Act., \& Eurosens. IX, Stockholm, Sweden, (1995) pp. 80-83.

[8] A. J. Fleischman, S. Roy, C. A. Zorman, and M. Mehregany, Proc. Intl. Conf. SiC, III-Nit. \& Related Mat., Stockholm, Sweden, (1998) pp. 889-892.

[9] G. Krotz, W. Legner, C. Wagner, H. Moller, H. Sonntag, and G. Muller, Proc. Intl. Conf. Solid-State Sens. \& Act., \& Eurosens. IX, Stockholm, Sweden, (1995) p. 186.

[10] A.J. Fleischman, S. Roy, C. A. Zorman, M. Mehregany, and L. G. Matus, Proc. IEEE MEMS Wkshp., San Diego, CA, (1996) pp. 234-238.

[11] R. K. Burla, S. Roy, V. M. Haria, C. A. Zorman, and M. Mehregany, Proc. Conf. Des., Charac., \& Packag. MEMS \& Microlect., SPIE Symp. Microelect. \& MEMS, Melbourne, Australia, (1999) pp. 324-333.

[12] W. Tang, Ph.D. Dissert., U.C. Berkeley, 1990.

[13] C. M. Su, M. Wuttig, A. Fekade, and M. Spencer, J. App. Phys., vol. 77, pp. 5611-5615, 1995.

[14] R. G. DeAnna, S. Roy, C. A. Zorman, and M. Mehregany, Proc. Intl. Conf. Mod. \& Sim. Microsyst. San Juan, Puerto Rico, (1999) pp.644-647.

[15] R. R. Reeber and K. Wang, Mat. Chem. \& Phys., v46, pp. 259-264, 1996.

[16] R. R. Reeber and K. Wang, Proc. Symp. Covalent Ceramics: Sci. \& Tech. Non-Oxides, MRS Fall Meeting, Boston, MA, (1995) pp. 211-216. 